\title{
Investigação da corrosão eletrolítica em telhas de aço recobertas com zincalume
}

\author{
Investigation of the electrolytic corrosion in \\ steel roof tiles coated with zincalume
}

\author{
Wagner Sade ${ }^{1}$, Rogério Antônio Xavier Nunes ${ }^{1}$, Victor Eric de Souza Moreira ${ }^{2}$, \\ Natália Brasil Dias Haneiko², Nilo Nogueira da Silva ${ }^{3}$
}

\footnotetext{
${ }^{1}$ Departamento de Engenharia Mecânica, CEFET (Centro Federal de Educação Tecnológica de Minas Gerais), Belo Horizonte, Minas Gerais, Brasil.

${ }^{2}$ Coordenação de Engenharia Metalúrgica, IFMG (Instituto Federal de Minas Gerais), Ouro Branco, Minas Gerais, Brasil.

${ }^{3}$ Departamento de Engenharia Mecânica, UFMG (Universidade Federal de Minas Gerais), Belo Horizonte, Minas Gerais, Brasil.

e-mail:wagnersade@ hotmail.com, rogerioxavier@cefetmg.br, victorericmoreira@ hotmail.com, natatabrasil@yahoo.com.br, nilons.fisica@gmail.com
}

\begin{abstract}
RESUMO
As telhas de aço usadas em galpões de fazendas expostas às intempéries ficam vulneráveis à degradação. A corrosão surge devido à diferença de potencial elétrico entre a superfície metálica e o meio, levando a um carregamento elétrico dessa superfície. Elas então necessitam da proteção de um recobrimento anticorrosivo, cujo objetivo é aumentar sua vida útil. Atualmente um recobrimento usado para diminuir os efeitos do sol e da chuva em telhas metálicas é o de zincalume, que consiste em uma liga de zinco e alumínio. Este recobrimento permite a combinação do zinco com alumínio, que alia a resistência por barreira do primeiro ao bom desempenho do segundo em proteger bordas e pequenas descontinuidades. Este produto mantém a força estrutural do aço-base e confere alta resistência à corrosão atmosférica, interrompendo a corrente elétrica. Neste trabalho foi analisada a degradação das telhas de aço recobertas com uma camada de zincalume sujeita à ação do tempo. Análises com fluorescência de raios X foram utilizadas a fim de se verificar a composição química das amostras estudadas. Foram realizadas também análises macrográficas e micrográficas, a fim de se avaliar a degradação das telhas.
\end{abstract}

Palavras chaves:Telhas de Aço, Corrosão, Recobrimento, Zincalume.

\section{ABSTRACT}

The steel roof tiles used in farm sheds are vulnerable to the action of weathering. The corrosion arises due to difference of electrical potential between the metallic surface and the environment, leading to an electrical load of this surface. They need a protection, an anticorrosive coating, whose purpose is to increase the lifetime. Zincalume is a kind of coating currently used to decrease the effects of sun and rain in the metal roof tiles. This coating consists of an alloy of zinc and aluminum. The Zincalume coating allows the combination of zinc and aluminum by combining the barrier resistance offered by the first one and the good performance of the second one in protecting edges and small discontinuities. This product maintains the structural strength of the steel base and provides high resistance to atmospheric corrosion leading to the interruption of the electrical current. The degradation of steel roofing coated with a layer of zincalume subject to weathering was analyzed in this work. Analysis with X-ray fluorescence was used to verify the chemical composition of the studied samples. Macrographic and micrographic analyzes were also carried out in order to evaluate the degradation of the roof tiles.

Keywords:Steel Roof Tiles, Corrosion, Coating, Zincalume. 


\section{INTRODUÇÃO}

A corrosão é um fenômeno que pode ser espontâneo ou não e quando não mitigado causa perdas materiais e econômicas. A corrosão em si relaciona-se com a diminuição do tempo de vida útil do material. Se o processo não for interrompido, dependendo do tipo de corrosão, as perdas e consequências podem ser catastróficas. Sendo assim, o presente trabalho tem por objetivo apresentar uma análise das possíveis causas da corrosão sofrida por telhas metalizadas com zincalume amostradas em um galpão de uma propriedade rural. A fim de garantir uma maior proteção contra a corrosão, as telhas de aço recobertas com zincalume foram revestidas com tinta verde epóxi, promovendo assim uma camada dúplex nas telhas de aço.

A corrosão é uma deterioração que ocorre em materiais metálicos ou não metálicos acarretando a perda de material. No caso dos metais este processo envolve reações de oxidação e redução, que ocorrem simultaneamente em toda superfície do material em contato com um agente oxidante. [1,2] Nos processos corrosivos espontâneos nas superfícies dos materiais metálicos provenientes de reações de oxidação de caráter eletrolítico, o material metálico é o agente redutor que sofre ação de agentes oxidantes. [3] O mecanismo eletrolítico envolve reações com transferência de cargas ou elétrons através de uma interface metal-eletrólito. Esse mecanismo ocorre quando a superfície de um material metálico está em contato com um meio aquoso, atmosférico, com o solo ou com eletrólitos solubilizados ou fundidos. [4,5] Estruturas como as telhas metálicas estão sujeitas a este fenômeno, as quais se comportam como eletrodos e promovem os efeitos químicos de oxidação e redução. Este tipo de corrosão ocorre devido à formação de uma pilha eletrolítica com geração de corrente elétrica. [6] Assim, ocorre a deterioração da superfície de um metal e a mesma é forçada a funcionar como anodo ativo.

A Figura 1 ilustra uma representação esquemática de uma célula eletrolítica. No anodo ocorre uma reação de oxidação (corrosão do material) e no catodo uma reação de redução.

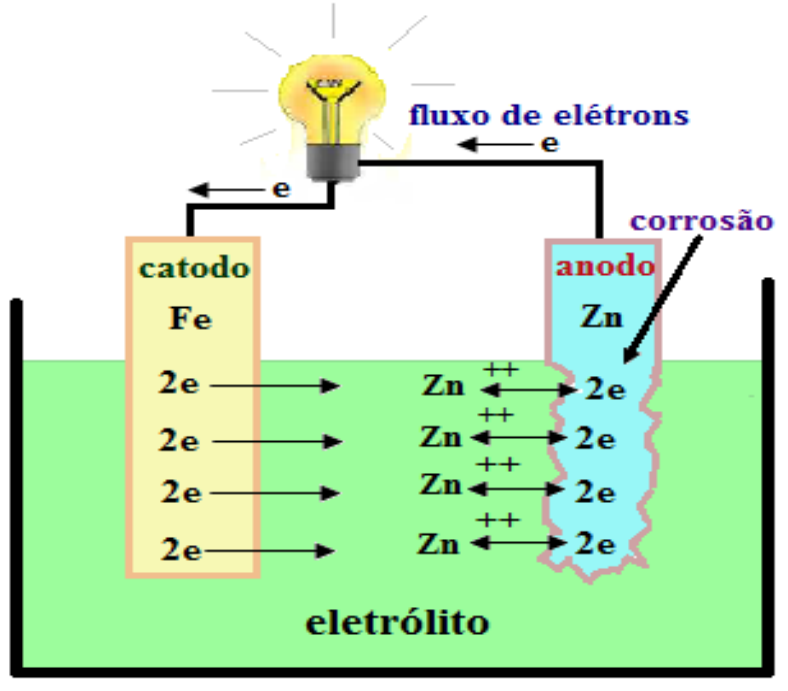

Figura 1: A célula de corrosão eletrolítica. [3]

Para que a pilha eletrolítica ocorra é necessário que os materiais do anodo e catodo apresentem potenciais de oxidação diferentes. [7]. Esta oxidação é definida como a tensão gerada pelo anodo e catodo em relação a um eletrodo neutro de referência, sendo ele o eletrodo de hidrogênio que é atribuído, por convenção, o valor zero para o seu potencial a $25^{\circ} \mathrm{C}$. Na prática, a corrosão acontece devido às diferenças de materiais existentes como: soldas, conexões ou simplesmente diferenças superficiais no mesmo metal. A maioria dos métodos de controle de corrosão consiste em intercalar uma camada protetora entre o metal e o meio corrosivo interrompendo a corrente elétrica responsável pela perda de material. [3] As telhas metálicas recebidas como amostras estiveram expostas às intempéries sofrendo o processo de corrosão durante 1 (um) ano. De forma que a degradação das telhas metálicas contou com o fator tempo como agravante.

\section{MATERIAIS E MÉTODOS}

Foi disponibilizada uma amostra de telha metálica oriunda da cobertura de um galpão. A telha recebida foi recortada para facilitar seu manuseio e a definição de regiões de interesse em função da mudança de coloração da camada de recobrimento. Todas estas regiões na amostra de telha foram fotografadas e submetidas a 
análises macrográficas. Foram também realizadas análises micrográficas conforme conveniência para aprofundar a investigação sobre a morfologia e espessura dos recobrimentos utilizados.

\subsection{O Material Analisado}

O material disponibilizado para análise foram as amostras das telhas de aço com recobrimento de zincalume, sendo o lado voltado para o exterior do galpão revestido, ainda, com uma película de tinta na cor verde.

Este recobrimento metálico comercialmente denominado zincalume conforme o fabricante consiste de uma liga com composição percentual de 43,5\% de zinco, com 55,0\% de alumínio e com 1,5\% de silício. O zincalume foi depositado sobre uma chapa de aço com $0,43 \mathrm{~mm}$ de espessura por meio de um processo contínuo de imersão a quente. A tinta utilizada como acabamento foi um composto a base de epóxi poliéster com espessura de $55 \mu \mathrm{m}$. Este recobrimento com duas camadas sobre a chapa de aço, sendo a $1^{\text {a }}$ camada de zincalume e a $2^{\mathrm{a}}$ camada de tinta epóxi verde, denomina-se recobrimento dúplex.

O material como recebido em sua vista de cima e de baixo é mostrado na Figura 2.

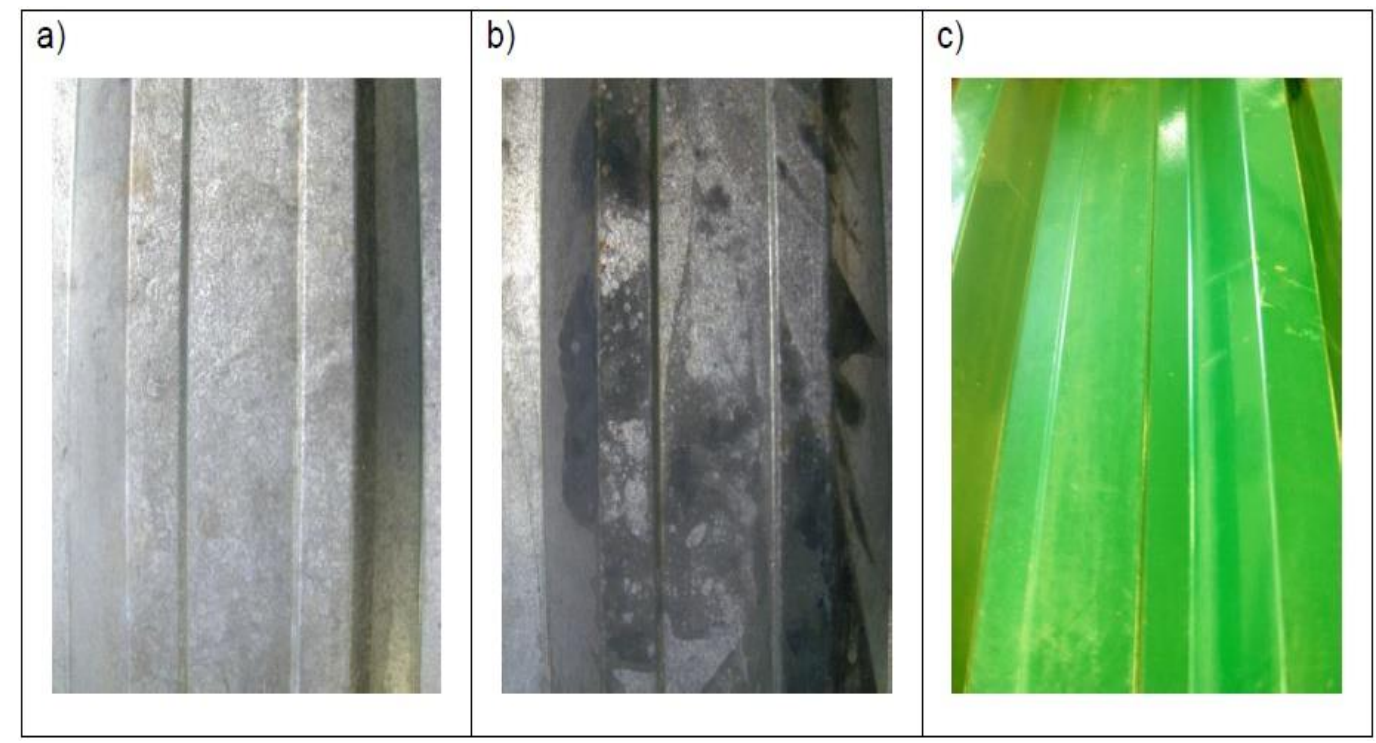

Figura 2: Fotografias tiradas dos materiais trabalhados. (a) parte de baixo da telha: recobrimento de zincalume, (b) recobrimento com anomalia e, (c) parte de cima da telha: revestimento de tinta epóxi verde sobre o recobrimento de zincalume.

\subsection{A Preparação das Amostras}

Os exames macroscópicos e microscópicos foram realizados a fim de se observar a degradação das amostras. Para facilitar o manuseio da amostra de telha e viabilizar as análises de composição química e micrográficas foi efetuado o recorte da telha recebida de acordo com um plano de ensaios.

\subsection{Análises Químicas}

As análises químicas das amostras foram realizadas com a fluorescência de raios $\mathrm{X}$ nas regiões: (a) do recobrimento com zincalume, (b) do recobrimento com anomalias e (c) do revestimento com tinta epóxi.

\subsection{Análises Macrográficas}

As análises macrográficas foram inicialmente realizadas por inspeção visual na telha como recebida. Uma máquina fotográfica digital foi utilizada para registrar o estado das superfícies das telhas e das regiões de interesse.

Uma inspeção visual e recursos para digitalização de imagens foram utilizados na medida em que um maior detalhamento das regiões de interesse se fez necessário. 


\subsection{Análises Micrográficas}

Os corpos de prova referentes a cada região de interesse foram previamente seccionados e lixados com lixas de $\mathrm{SiC}$ de granulometria 240, 400, 600, 800 e 1500 mesh.

As análises micrográficas foram realizadas com auxílio do microscópio eletrônico de varredura (MEV). Os corpos de prova foram observados nas condições como recebidos e sem ataque químico.

\section{RESULTADOS E DISCUSSÃO}

Ficou evidente que as telhas analisadas sofreram degradação devida à exposição às intempéries. O recobrimento das amostras não possuía uniformidade por causa da formação de canais de infiltração de água, que favorecia, também, a formação de produtos de corrosão ao longo das superfícies das telhas. A degradação do material e as manchas encontradas nas amostras de telhas foram investigadas nas etapas seguintes da análise.

\subsection{A Composição Química}

As análises de composição química das amostras das telhas recobertas com zincalume e aquelas com degradação estão apresentadas na Tabela 1, assim como os desvios padrão encontrados. Para avaliação da composição química da amostra foram analisadas réplicas.

Tabela 1: Composição química em peso $(\% \mathrm{p} / \mathrm{p})$ das amostras recebidas

\begin{tabular}{c|c|c|c}
\hline & $\begin{array}{c}\text { Telhas Sem } \\
\text { Degradações }\end{array}$ & $\begin{array}{c}\text { Telhas com De- } \\
\text { gradações nas } \\
\text { Áreas Claras }\end{array}$ & $\begin{array}{c}\text { Telhas com Degra- } \\
\text { dações nas Áreas } \\
\text { Escuras }\end{array}$ \\
\hline $\mathrm{Al}$ & $50,09 \pm 0,08$ & $50,59 \pm 0,07$ & $48,57 \pm 0,05$ \\
$\mathrm{Zn}$ & $31,89 \pm 0,07$ & $31,14 \pm 0,03$ & $33,75 \pm 0,08$ \\
$\mathrm{Si}$ & $0,97 \pm 0,06$ & $0,91 \pm 0,02$ & $0,57 \pm 0,07$ \\
$\mathrm{Fe}$ & $15,75 \pm 0,04$ & $16,41 \pm 0,04$ & $15,45 \pm 0,03$ \\
$\mathrm{Mn}$ & $0,11 \pm 0,01$ & $0,07 \pm 0,01$ & $0,09 \pm 0,02$ \\
$\mathrm{Cr}$ & $0,18 \pm 0,01$ & $0,06 \pm 0,03$ & $0,05 \pm 0,01$ \\
$\mathrm{~S}$ & $0,50 \pm 0,02$ & $0,80 \pm 0,07$ & $1,50 \pm 0,05$ \\
\hline
\end{tabular}

Os resultados indicam uma redução da concentração de alumínio, zinco e silício no recobrimento de zincalume em relação àqueles fornecidos pelo fabricante. A presença de ferro na composição do recobrimento indica que o feixe de difração de raios X utilizado na técnica de fluorescência alcançou o material de base da telha, que é a chapa de aço.

A presença de enxofre nas amostras recobertas com zincalume e nas amostras com degradação, áreas claras e escuras, foi observada. Nota-se que as porcentagens em peso de enxofre aumentam de acordo com as áreas afetadas. As áreas escuras são aquelas que apresentam maiores degradações. Como um dos principais contaminantes presente na atmosfera é o dióxido de enxofre, este exerce uma influência importante na corrosão das telhas [8].

O dióxido de enxofre é captado pela umidade das partículas de pó oxidando-se por processos catalíticos e formando ácido sulfúrico que se deposita em gotículas microscópicas nas superfícies expostas, juntamente com uma parte de dióxido de enxofre e de ácido sulfuroso. O resultado é que os contaminantes da atmosfera juntamente com sua umidade, produzem uma película de ácido altamente corrosivo nas superfícies expostas das telhas $[9,10]$. 


\subsection{Análises Macrográficas}

Esta etapa do trabalho possibilitou a identificação de regiões com evidências relevantes para a caracterização de corrosão.

Importante destacar, que pela inspeção visual ficou evidente a presença de 04 (quatro) regiões de interesse na superfície das telhas como na Figura 3, sendo elas: os recobrimentos de zincalume "na cor prata" (Região 1), "na cor cinza" (Região 2), "na cor preta" (Região 3) e o revestimento de tinta epóxi poliéster (Região 4).

\begin{tabular}{|c|c|c|}
\hline Regiões & Campo Representativo & Observações \\
\hline 1 & Zincalume prata & $\begin{array}{l}\text { 1. Ausência de riscos aparentes na su- } \\
\text { perfície da amostra; } \\
\text { 2. Ausência de manchas escuras na } \\
\text { superfície da amostra. }\end{array}$ \\
\hline 2 & Zincalume cinza & $\begin{array}{l}\text { 1. Ausência de riscos aparentes na su- } \\
\text { perfície da amostra; } \\
\text { 2. Presença de manchas acinzentadas } \\
\text { na superfície da amostra; } \\
\text { 3. Presença de manchas de tinta verde } \\
\text { na superfície do recobrimento de Zin- } \\
\text { calume (destaque). }\end{array}$ \\
\hline 3 & Zincalume preto & $\begin{array}{l}\text { 1. Ausência de riscos aparentes na su- } \\
\text { perfície da amostra; } \\
\text { 2. Presença de manchas negras na su- } \\
\text { perfície da amostra. }\end{array}$ \\
\hline 4 & Tinta epóxi poliéster & $\begin{array}{l}\text { 1. Ausência de riscos aparentes na su- } \\
\text { perfície da amostra; } \\
\text { 2. Ausência de manchas na superfície } \\
\text { da amostra. }\end{array}$ \\
\hline
\end{tabular}

Figura 3: Regiões de interesse de estudo das telhas metálicas como recebidas. 


\subsubsection{Análise Macrográfica da Região 1}

Observou-se uma granulação grosseira no recobrimento com zincalume conforme Figura 4. Esse lado da telha, sem pintura, voltado para o interior do galpão com tal morfologia estaria vulnerável à corrosão. A inspeção visual não revelou falhas ou riscamentos na superfície das amostras.

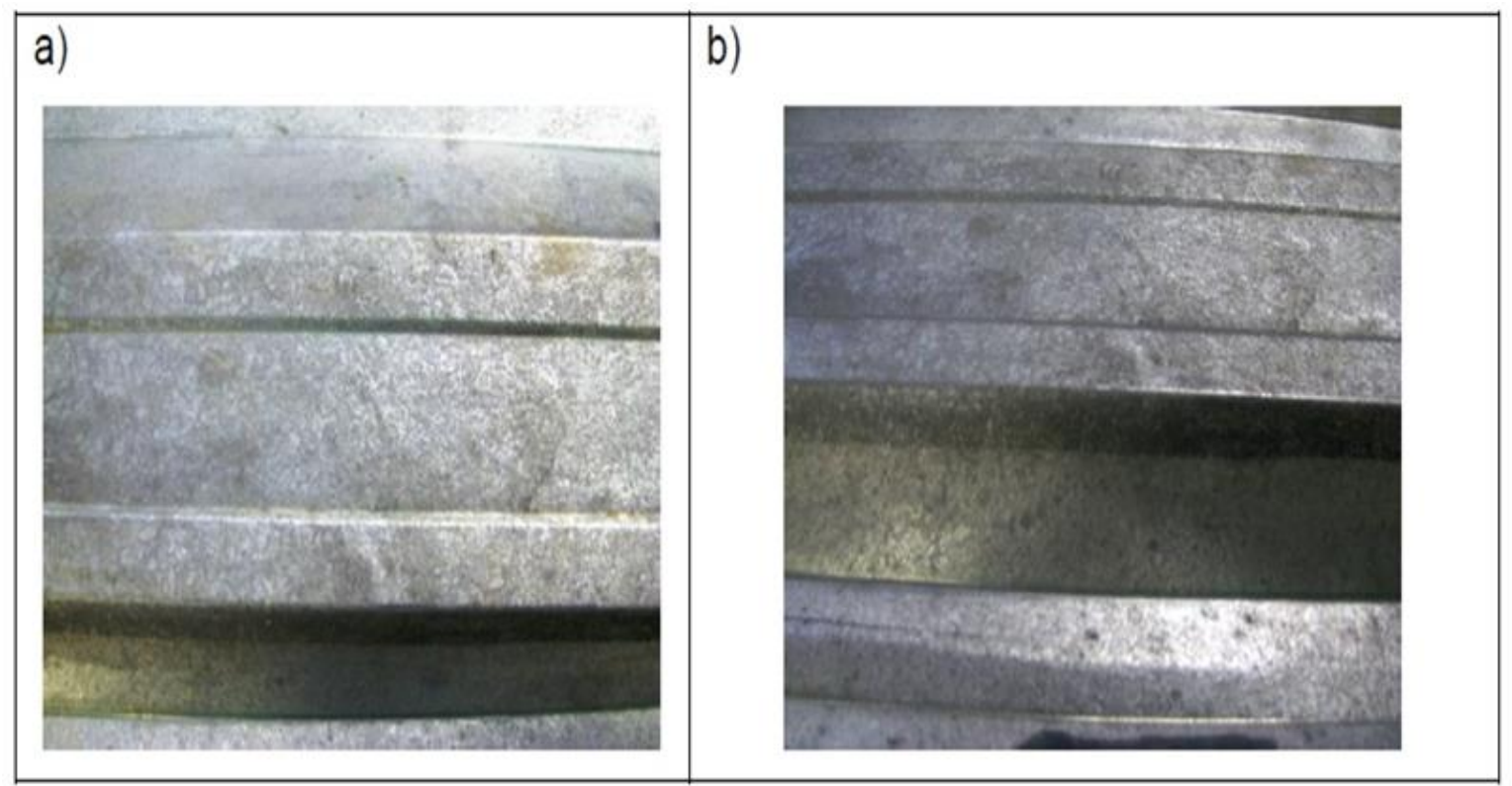

Figura 4: Vistas da região 1: (a) incidência na "capa"; (b) incidência na "bica" e na lateral da telha.

\subsubsection{Análise Macrográfica da Região 2}

Ao longo do recobrimento com zincalume também foi observada uma camada escura, com granulação grosseira, não havendo falhas ou riscamentos na superfície das amostras, Figura 5.

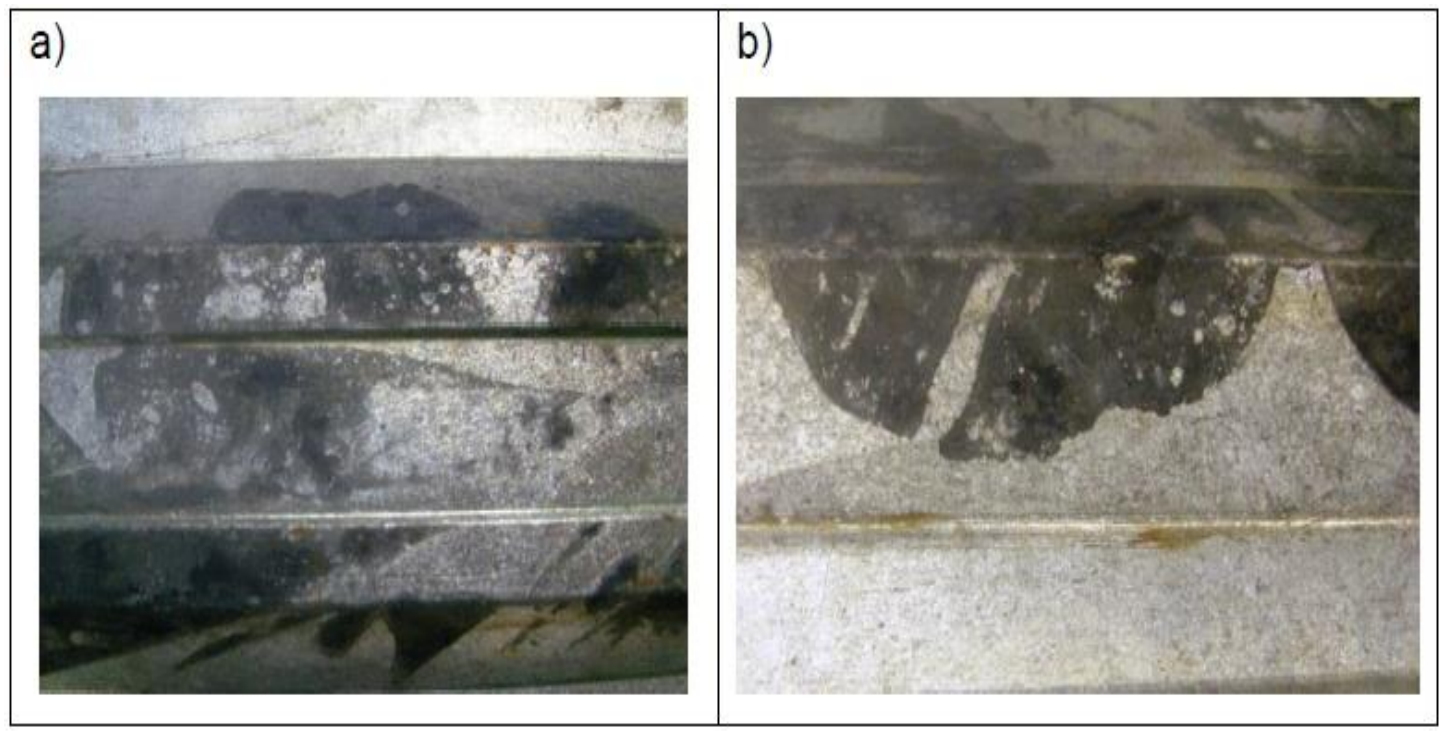

Figura 5: Vistas da região 2: (a) incidência na "capa" da telha; (b) incidência na "bica" e na lateral da telha. 


\subsubsection{Análise Macrográfica da Região 3}

Na região da telha em que é encontrado o recobrimento de zincalume negro não foi possível observar o aspecto dos grãos formadores da camada, Figura 6.

Novamente, não foram observadas falhas ou riscamentos na superfície das amostras ao longo do recobrimento com zincalume. Também nesta imagem foi observada uma camada escura com granulação grosseira

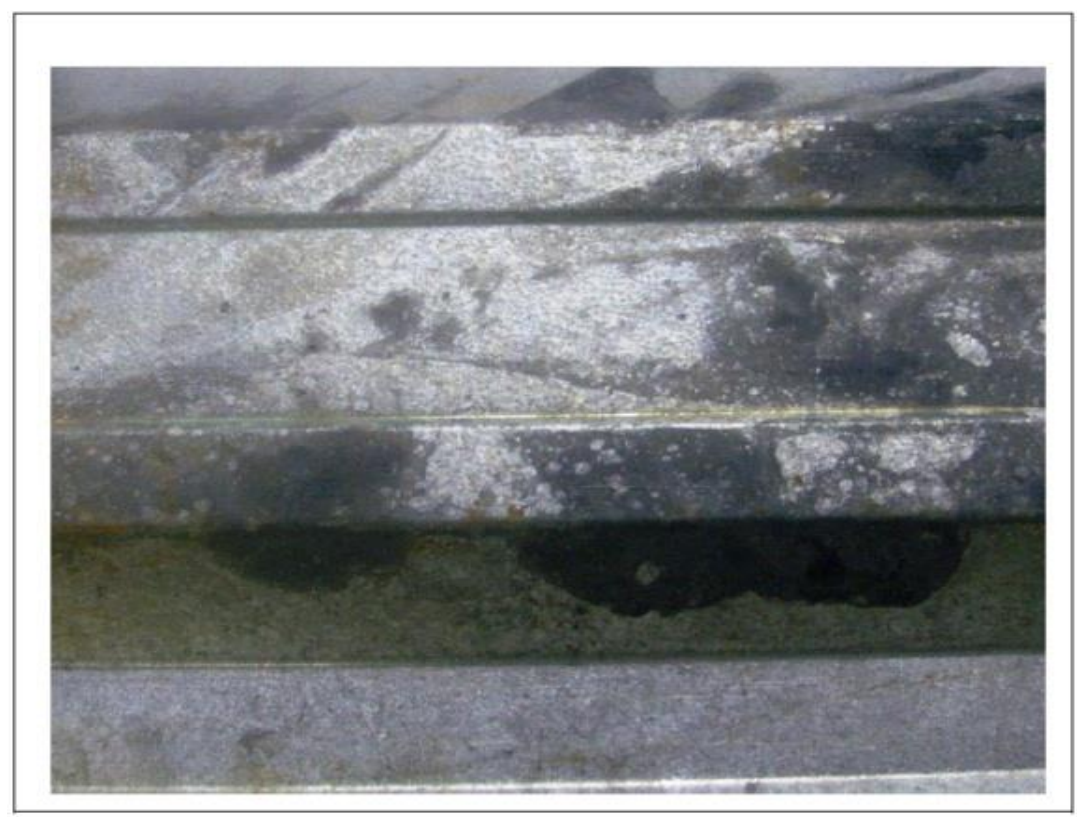

Figura 6: Vista da região 3: incidência na "capa" e na lateral da telha.

\subsubsection{Análise Macrográfica da Região 4}

Foi observado no recobrimento de tinta epóxi poliéster de cor verde, lado da telha voltado para o exterior do galpão, regiões com suave mudança de tonalidade de cor. Não foram observadas falhas ou riscamentos na superfície, conforme Figura 7.

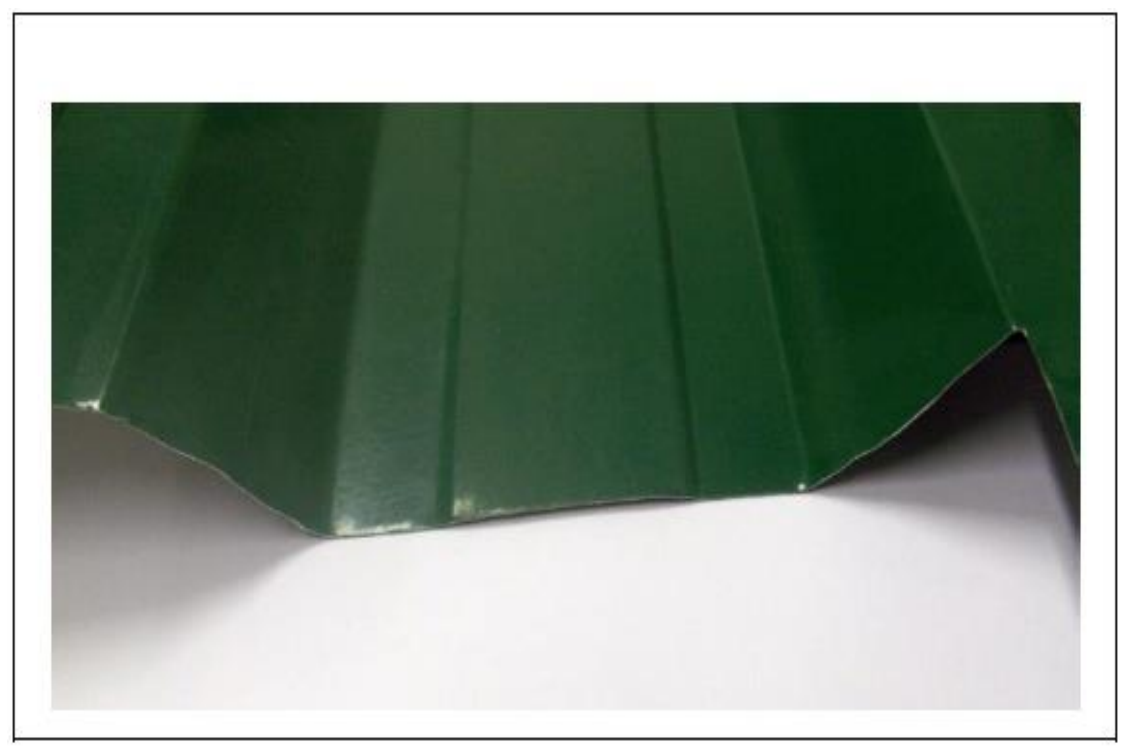

Figura 7: Vista da região 4: recobrimento de tinta epóxi poliéster. 


\subsection{Análises Micrográficas}

Através da análise da seção transversal da telha de aço recoberta com zincalume com tinta epóxi, notou-se uma variação de espessura de 15 a $30 \mu \mathrm{m}$ no recobrimento de zincalume, indicando perda de material. Foram notadas também descontinuidades, vazios e poros no recobrimento.

Essas falhas podem estar relacionadas com o processo de deposição com zincalume realizado por imersão a quente. Estes resultados foram repetidos para todas as regiões analisadas.

Foram observadas na Figura 8 estas irregularidades, que são uma consequência da corrosão eletrolítica no recobrimento de zincalume.

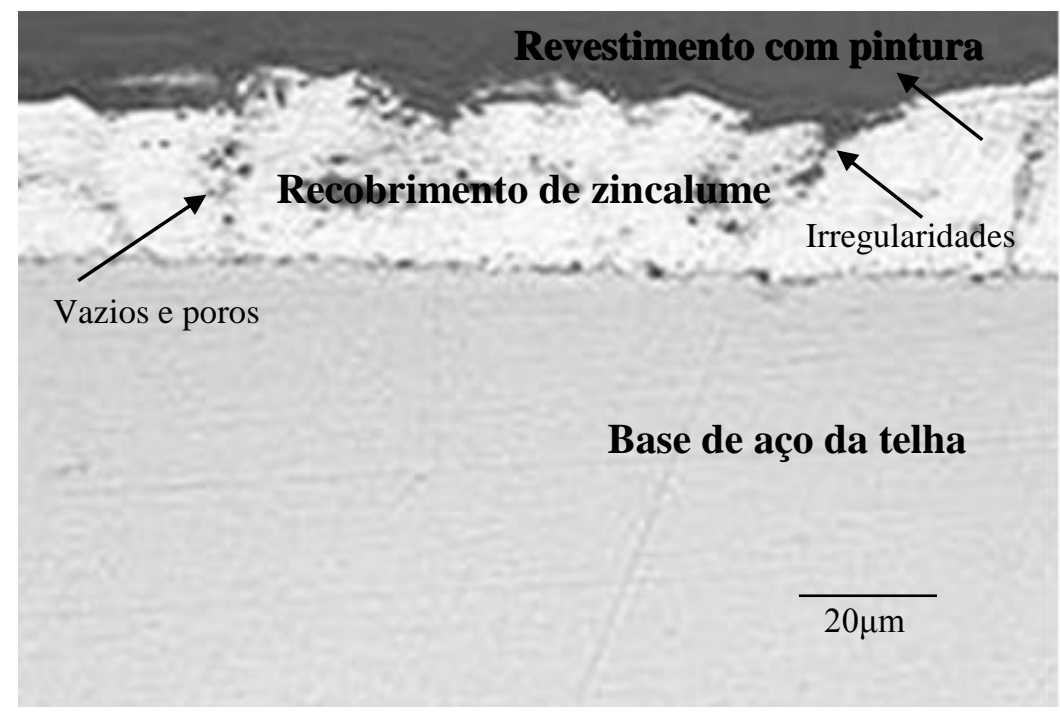

Figura 8: Telha metálica recoberta com zincalume e tinta epóxi poliéster.

A Figura 9(a) é uma imagem visual da telha como recebida. Foi marcada em círculo vermelho a Região 3 (de zincalume preto), que corresponde à corrosão em sua superfície. Na Figura 9(b) uma amostra desta mesma região foi observada ao MEV em uma escala de $20 \mu \mathrm{m}$ que mostrou o contraste das manchas de corrosão.

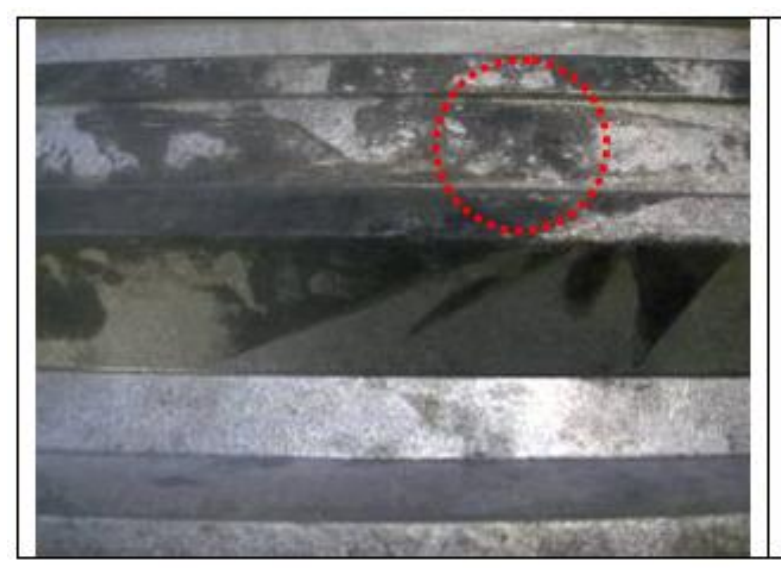

(a)

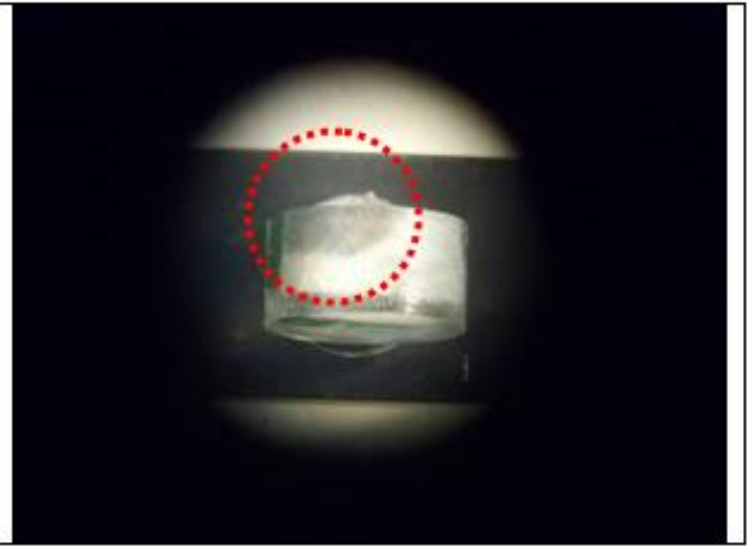

(b)

Figura 9: Região 3 da telha como recebida (a) e em escala de $20 \mu \mathrm{m}$ mostrando manchas de corrosão (b). 


\section{CONCLUSÕES}

De acordo com as análises químicas o teor de enxofre nas amostras aumentou com a degradação das telhas. Esta formação de sulfetos, responsável pela cor cinza nas áreas escuras colaborou para a deterioração das mesmas.

A presença de enxofre na camada de metalização - zincalume - resultando na formação de sulfeto de zinco na superfície das telhas culminou com o escurecimento das regiões afetadas.

A espessura das telhas que não foi homogênea e a presença de descontinuidades na camada de metalização revelou um recobrimento de qualidade inferior aos padrões encontrados no mercado.

A localização da fazenda, próxima de áreas industriais, colaborou para o processo de corrosão, devido ao desprendimento de gases de enxofre das fábricas, causando chuva ácida à base de ácido sulfúrico.

Enfim, conclui-se que o processo de recobrimento com zincalume por imersão a quente não foi de boa qualidade, o que agravou a corrosão, proporcionando a presença de correntes elétricas e a consequente perda de material.

\section{BIBLIOGRAFIA}

[1] ASM HANDBOOK INTERNATIONAL COMMITTEE, Corrosion, 9. ed., v. 13, USA, Ohio, Metals Handbook, 1987.

[2] BIDETTI, B. B., BALTHAZAR, P. A., VAZ, E. L. S., et al., Uma Experiência Didática de Corrosão Usando Colorimetria Visual, Departamento de Física e Química, Faculdade de Engenharia de Guaratinguetá, São Paulo, Ed. Universidade Estadual Paulista, 2011.

[3] GENTIL, V., Corrosão, 6. ed, Rio de Janeiro, Editora LTC, 2011.

[4] LINS, V. F. C., LAGE, F. C., CASTRO, M. M. R., et al., "Strategies for Corrosion Inhibition of Slurry Pipelines Prior to Commissioning", Revista Escola de Minas, v. 69, n.2, pp. 161-166, 2016.

[5] CARVALHO, C. C. A., SILVA, M.M.N., GOMES, W.V., et al., "Análise do Processo Corrosivo Sofrido nos Equipamentos e Tubulações do Reservatório de Abastecimento Hídrico da Cidade de Pau dos Ferros", In: Congresso Técnico Científico da Engenharia e da Agronomia CONTECC2016, Foz do Iguaçu, Paraná, Brasil, 29 setembro - 1 agosto 2016.

[6] WINTERS, N., GRANUKE, K., MCCALL, M., "Roofing Materials Assessment: Investigation of Five Metals in Runoff from Roofing Materials", Water Environment Research, v.87, n. 9, 2015.

[7] HUANG, H., PAN, Z., GUO, X., et al., "Effect of an Alternating Electric Field on the Atmospheric Corrosion Behaviour of Copper under a Thin Electrolyte Layer", Corrosion Science, v. 75, pp. 100-105, 2013.

[8] RODRIGUES, L. M., Estudo da Corrosão do Aço para Dutos API 5L X56 em Solos do RS, Tese de D.Sc., Universidade Federal do Rio Grande do Sul, Porto Alegre, RS, Brasil, 2006.

[9] SILVA, C. A., Análise de Propriedades Mecânicas, Tribológicas e Metalográficas de Material Submetido ao Processo de Erosão-Corrosão com Sulfetação, Dissertação de M.Sc., Universidade Federal do Paraná, Curitiba, Paraná, Brasil, 2009.

[10] PALHARIM, P. H., SILVA, S.N., RODRIGUES, L.M., et al., "Efeito da Concentração de $\mathrm{H}_{2} \mathrm{SO}_{4}$ na Corrosão Atmosférica de Tubos de Trocadores de Calor", In: Anais do VII Salão Internacional de Ensino, Pesquisa e Extensão, Universidade Federal do Pampa, v. 7, n. 2, Bagé, RS, Brasil, 2015.

\section{ORCID}

Victor Eric de Souza Moreira

Wagner Sade

Rogério Antônio Xavier Nunes

Nilo Nogueira Silva

Natália Brasil Dias Haneiko https://orcid.org/0000-0001-8039-3892

https://orcid.org/0000-0001-7457-9068

https://orcid.org/0000-0003-0376-6469

https://orcid.org/0000-0002-7395-9349

https://orcid.org/0000-0002-2901-9085 